\title{
Crew Exploration Vehicle Launch Abort System Flight Test Overview
}

\author{
Peggy S. Williams-Hayes ${ }^{*}$ \\ NASA Dryden Flight Research Center, Edwards, California, 93523
}

\begin{abstract}
The Constellation program is an organization within NASA whose mission is to create the new generation of spacecraft that will replace the Space Shuttle after its planned retirement in 2010. In the event of a catastrophic failure on the launch pad or launch vehicle during ascent, the successful use of the launch abort system will allow crew members to escape harm. The Flight Test Office is the organization within the Constellation project that will flight-test the launch abort system on the Orion crew exploration vehicle. The Flight Test Office has proposed six tests that will demonstrate the use of the launch abort system. These flight tests will be performed at the White Sands Missile Range in New Mexico and are similar in nature to the Apollo Little Joe II tests performed in the 1960s. An overview of the launch abort system flight tests for the Orion crew exploration vehicle is given. Details on the configuration of the first pad abort flight test are discussed. Sample flight trajectories for two of the six flight tests are shown.
\end{abstract}

$\begin{array}{ll} & \\ \text { AA } & =\text { ascent abort flight test } \\ \text { ACM } & =\text { Nomenclature } \\ \text { ANTARES } & =\text { Johnson Space Center CEV/CLV nonlinear simulation } \\ \text { ATB } & =\text { abort test booster } \\ \text { BPC } & =\text { boost protective cover } \\ \text { CEV } & =\text { crew exploration vehicle } \\ \text { CLV } & =\text { crew launch vehicle } \\ \text { CM } & =\text { crew module } \\ \text { cg } & =\text { center of gravity } \\ \text { FTA } & =\text { flight test article } \\ \text { LAS } & =\text { launch abort system } \\ \text { LAV } & =\text { launch abort vehicle } \\ \text { LaRC } & =\text { Langley Research Center } \\ \text { LM } & =\text { Lockheed Martin Corporation } \\ \text { OML } & =\text { outer mold line } \\ \text { PA } & =\text { pad abort flight test } \\ \text { WSMR } & =\text { White Sands Missile Range }\end{array}$

\section{Introduction}

$\mathrm{T}$

HE purpose of the NASA Constellation project is to create a new generation of spacecraft for human flight to the International Space Station in low-Earth orbit, to the lunar surface, as well as for use in future deep-space exploration. ${ }^{1}$ One portion of the Constellation program is the development of the Orion crew exploration vehicle (CEV) to be used in spaceflight. The Orion spacecraft consists of a crew module (CM), service module, space adapter, and launch abort system (LAS) ${ }^{2}$ The CM will hold as many as six crewmembers. The Orion CEV is similar in design to the Apollo space capsules, ${ }^{3}$ although larger and more massive.

The Flight Test Office is an organization within the Constellation program dedicated to the flight test of the LAS rocket used to initiate pad, mid-, and high-altitude aborts. In the event of a catastrophic failure on the launch pad or during the early ascent portion of spaceflight, the LAS will initiate an abort that will pull the crew module to a safe

${ }^{*}$ Aerospace Engineer, Controls and Dynamics Branch, M/S 4840D, AIAA member. 
distance away from the launch pad or failed booster. The Flight Test Office team has currently proposed six unmanned flight tests - two launch pad abort (PA) tests, without an external booster, and four ascent abort (AA) tests, utilizing a government-supplied test booster. The Flight Test Office team includes members from several NASA centers - Dryden Flight Research Center (Edwards, California), Johnson Space Center (Houston, Texas), Langley Research Center (Langley, Virginia), and Glenn Research Center (Cleveland, Ohio). Additional team members include Lockheed Martin Space Systems Corporation (Denver, Colorado), Orbital Sciences (Dulles, Virginia), and Orbital Sciences (Chandler, Arizona). Whereas NASA is the responsible test organization, Orbital Sciences (Virginia) is responsible for the LAS, and Lockheed Martin (LM), the prime contractor, is designing and building key subsystems including the crew module avionics, the operational flight instrumentation system, and the flight software. Orbital Sciences (Arizona) will be providing the abort test booster used for the AA flight tests.

The vehicles to be flight-tested are known as Flight Test Articles (FTA). The FTAs (Fig. 1) will have different configurations based on the type of flight test performed. The FTA configuration is selected based on the operational vehicle design; however, time constraints on the abort flight tests, along with the fact that the flight test results will be used in the design of the operational vehicle, don't allow the operational vehicle configuration to be exactly duplicated in all of the FTAs. For the first launch pad abort test (PA-1), the FTA consists of a government-built boilerplate crew module and the launch abort system, built by Orbital Sciences, with avionics and flight software furnished by Lockheed Martin. The proposed flight test date for PA-1 is in the fall of 2008, launching from the White Sands Missile Range (WSMR) in New Mexico. The focus of the PA-1 test is engineering development and data acquisition, not certification.

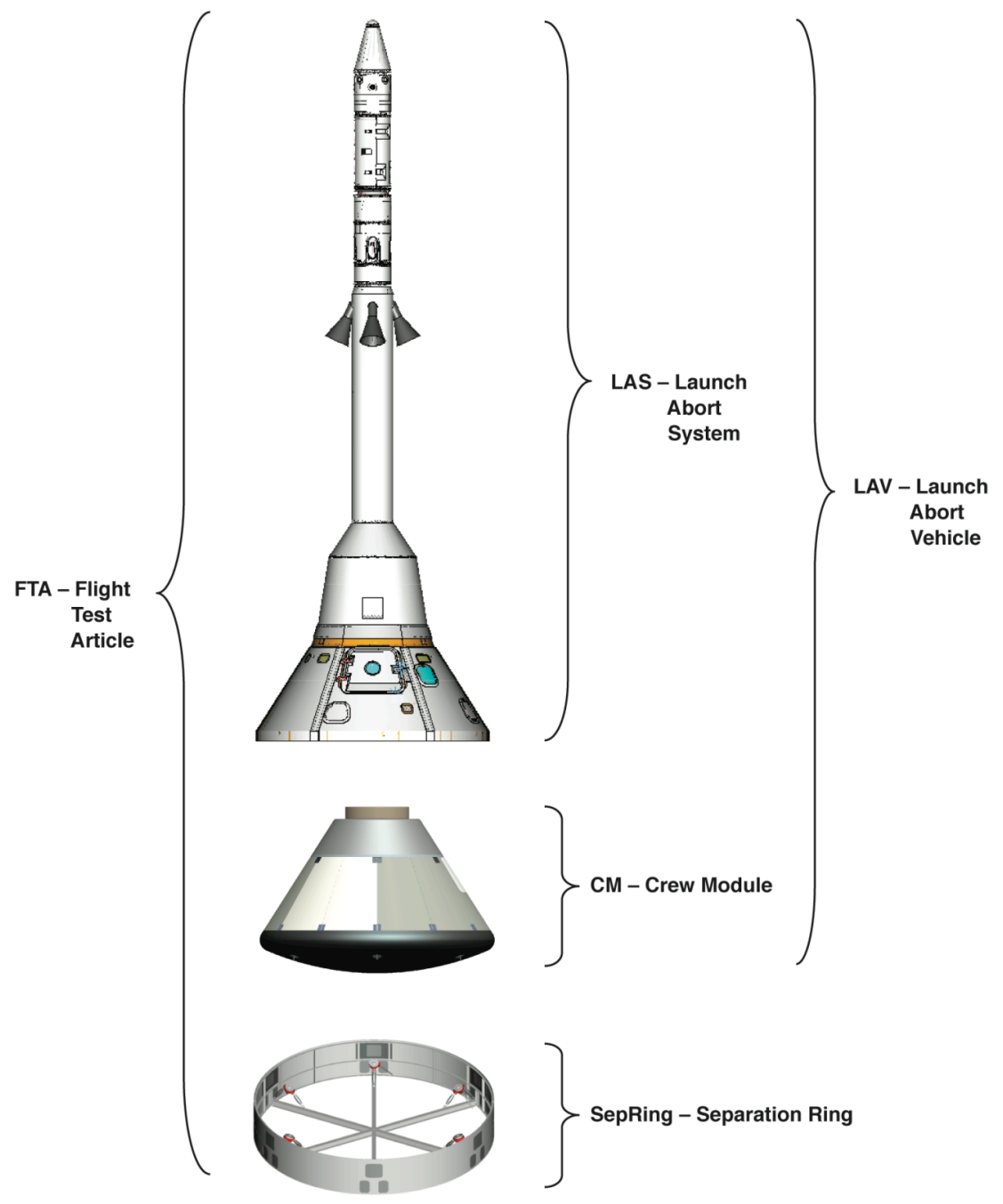

Figure 1. Flight test article. 


\section{Flight Test Description}

There are six flight tests currently proposed for the LAS aborts. The two pad abort flight tests (PA-1 and PA-2) occur from the launch pad. The four AA flight tests will use an abort test booster (ATB) specially designed for the LAS flight tests by Orbital Sciences (Arizona). The ATB will deliver the crew module and LAS to a specific flight condition to complete the tests described in Table 1.

Table 1. Abort flight test description.

\begin{tabular}{|c|c|c|c|}
\hline $\begin{array}{c}\text { Flight Test } \\
\text { (in chronological order) }\end{array}$ & Test Description & CM Description & LAS Description \\
\hline PA-1 & Abort from launch pad & $\begin{array}{c}\text { NASA provided } \\
\text { boilerplate }\end{array}$ & Flight test specific \\
\hline AA-1 & $\begin{array}{l}\text { Maximum dynamic } \\
\text { pressure abort }\end{array}$ & $\begin{array}{l}\text { NASA provided } \\
\text { boilerplate }\end{array}$ & Flight test specific \\
\hline PA-2 & $\begin{array}{l}\text { Abort from launch pad } \\
\text { with flight-like abort } \\
\text { trajectory }\end{array}$ & $\begin{array}{l}\text { LM produced; } \\
\text { more flight-like } \\
\text { structure }\end{array}$ & Operational \\
\hline AA-2 & Transonic abort & $\begin{array}{l}\text { LM produced } \\
\text { Operational }\end{array}$ & Operational \\
\hline AA-3 & $\begin{array}{l}\text { Off-nominal maximum } \\
\text { dynamic pressure abort }\end{array}$ & $\begin{array}{l}\text { LM produced } \\
\text { Operational }\end{array}$ & Operational \\
\hline $\mathrm{AA}-4$ & $\begin{array}{c}\text { High altitude } \\
\text { abort* }\end{array}$ & $\begin{array}{l}\text { LM produced } \\
\text { Operational }\end{array}$ & Operational \\
\hline
\end{tabular}

*government-supplied ATB may be replaced with Ares launch vehicle and launched out of Kennedy Space Center (Florida).

\section{Vehicle Configuration}

The flight test vehicle is made up of a crew module and launch abort system, that together during ascent form the launch abort vehicle (LAV). The flight test article is made up of the components of what is launched for each flight test. For PA-1, the flight test article consists of the CM, LAS, service module sub-section and the separation ring. For AA-1, the flight test article consists of the components of the PA-1 vehicle as well as an abort test booster that will carry the vehicle to a flight condition chosen specifically for AA-1.

\section{A. Crew Module Description}

The CM boilerplate vehicle for PA-1 is being built by the NASA Langley Research Center (LaRC). The boilerplate vehicles are not representative in structure of the operational crew modules, but have an outer mold line (OML) that is representative of the operational vehicle. Langley will provide two boilerplate CM articles for use in PA-1 and AA-1 flight tests. After the completion of AA-1, the CMs used in flight test will be designed and built by the prime contractor, Lockheed Martin.

The boilerplate $\mathrm{CM}$ is designed to match mass properties targets that are reasonable reflections of the mass properties of future operational vehicles. The mass properties targets for the PA-1 FTA were chosen based on the weight limit of the first generation parachutes and a desire to match the center of gravity (cg) value of the operational CM. For the PA-1 mass properties targets, the CM has an under drogue parachute mass of 17,167 lbm. Ballast is used in the boilerplate CM to obtain flight-like cg values for the crew module. The LAS used for the PA-1 flight tests will be heavier than the operational LAS because of manufacturing lead time. Therefore, the cg of the combined crew module and LAS, called the launch abort vehicle (LAV), is further forward than the operational LAV cg. This results in a more statically stable vehicle during ascent for PA-1. Mass properties targets for future abort flight test vehicles will be selected based on the operational configuration at the time of the flight test as well as other constraints, such as parachute design weight and dynamic pressure limits. Since the operational vehicle design is still being refined, mass properties targets for PA-2 as well as the four AA flight tests have yet to be identified. 


\section{B. Launch Abort System Description}

The LAS is being built by Orbital Sciences of Dulles, Virginia. The configuration of the LAS to be used for flight test is heavier than the operational LAS, because of the time constraints of vehicle delivery and the lead time required to manufacture with lighter materials. The LAS (Fig. 2) consists of an abort motor, an attitude control motor (ACM), and a jettison motor. The process of an LAS abort, as designed, would utilize these motors to pull the crew module away from the launch pad or malfunctioning booster. The abort motor has four nozzles canted away from the main housing case at an angle of $25^{\circ}$ (Fig. 2). The abort motor will deliver the majority of its thrust within the first four seconds after ignition, providing $15 \mathrm{~g}$ of acceleration away from the launch pad or failed launch vehicle (Fig. 3).

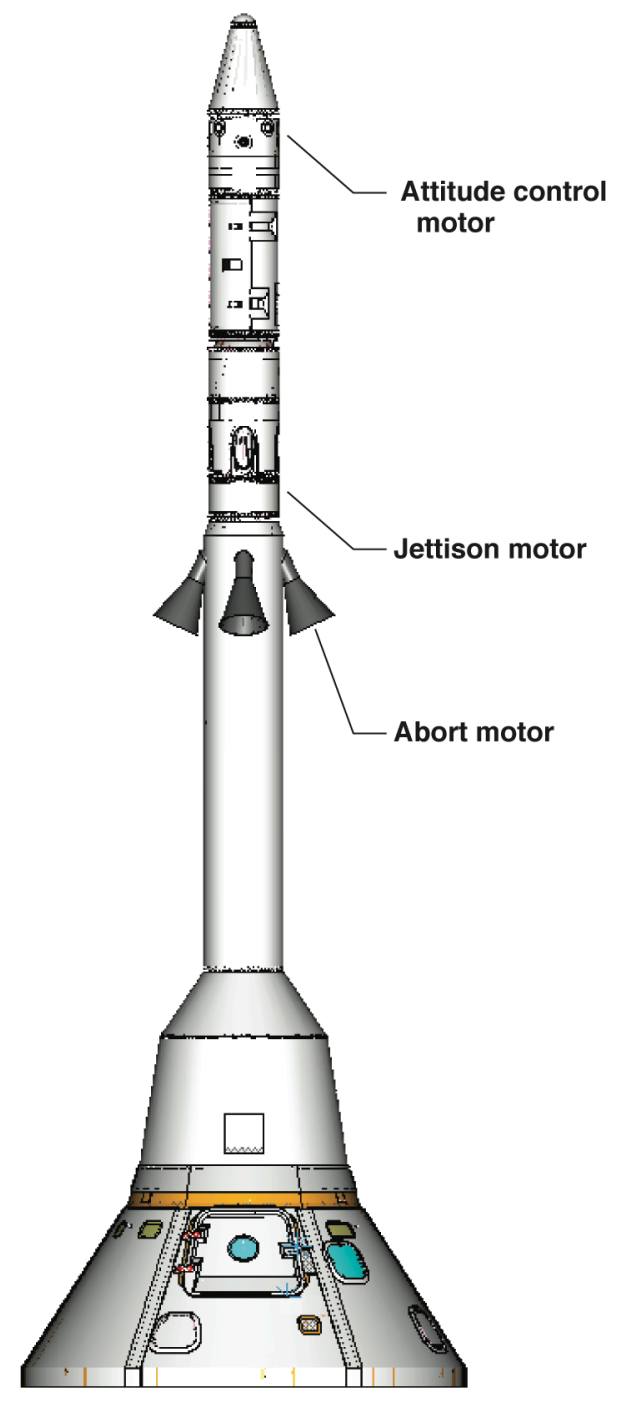

Figure 2. Launch abort system.

At the same time the abort motor would fire, the ACM would fire to maintain stable flight. The ACM consists of eight equally spaced nozzles, each $45^{\circ}$ apart around the LAS housing near the top of the casing. These eight nozzles will provide the ability to control motion in the pitch and yaw axes (Fig. 4). The ACM will burn for approximately $20 \mathrm{~s}$, providing thrust that can be diverted through the eight nozzles to produce controlling moments. After the abort motor burns out and the LAV is stabilized, the two canards on the LAS will deploy, and the combination of the canards and ACM will reorient the crew module and LAS so that the heat shield on the bottom of the crew module would be forward with respect to the air stream. 


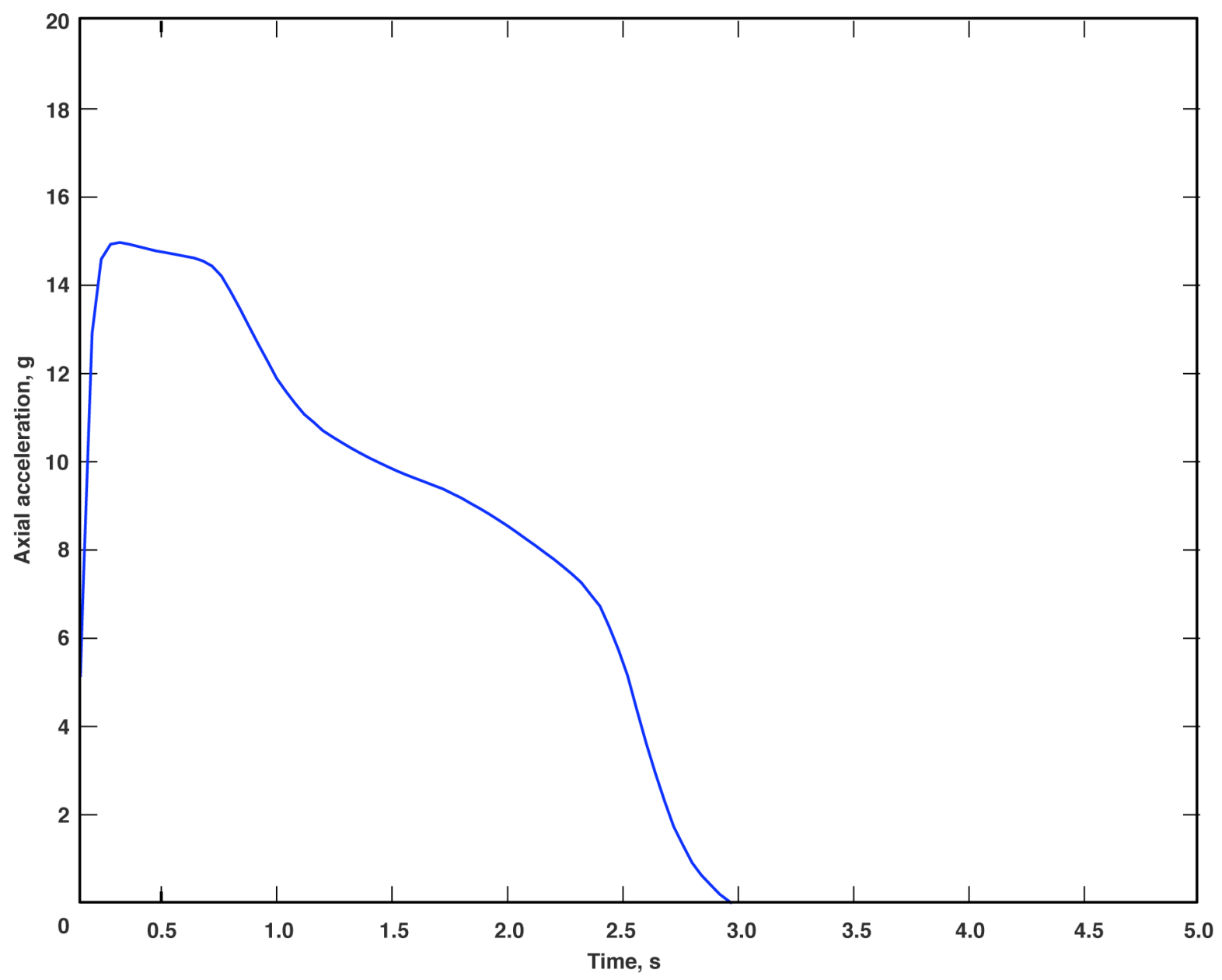

Figure 3. Axial acceleration resulting from LAS abort motor firing for pad abort.

Once the LAV reorients with the heat shield forward, the LAS jettison motor will fire and provide the impulse necessary to separate the LAS from the CM after the LAV is stabilized. The jettison motor contains four nozzles canted at $35^{\circ}$ from the case. The jettison motor provides approximately $41,000 \mathrm{lbf}$ of thrust in $1.5 \mathrm{~s}$.

The boost protective cover (BPC) is a mainly fiberglass material covering the crew module that provides protection during ascent or in the case of an abort. The BPC is ejected from the crew module with the LAS during LAS jettison. 


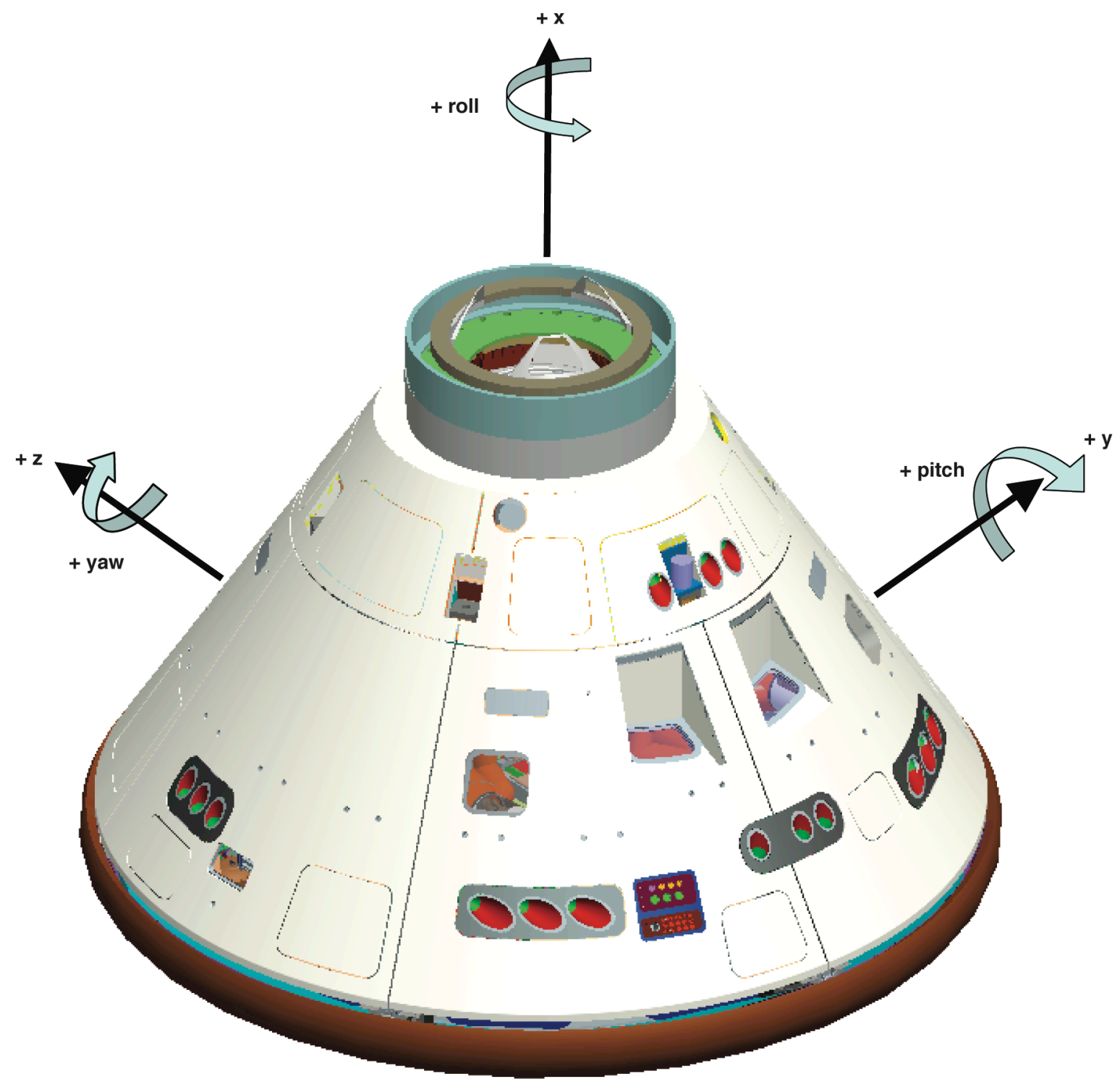

Figure 4. Crew module reference frame.

\section{Flight Test Description}

The LAS flight tests will occur at White Sands Missile Range in New Mexico. The initial site selection for PA-1 is near launch complex 32 and is slated to be launched in a due north direction relative to the launch pad.

The primary flight test objectives for PA-1 are to demonstrate a ground-initiated abort as well as to demonstrate the capability of the LAS to propel the crew module to a safe distance from a launch vehicle. Objectives specifically related to each subsystem are shown in Table 2 below. ${ }^{4}$ 
Table 2. Flight test objectives summary for PA-1.

\begin{tabular}{|c|c|}
\hline $\begin{array}{c}\text { Subsystem } \\
\text { Event description }\end{array}$ & Flight Test Objectives \\
\hline LAV & $\begin{array}{l}\text { Demonstration of stability and control of LAV during ascent } \\
\text { - Obtain structural loads data at the LAS-crew module } \\
\text { interfaces }\end{array}$ \\
\hline LAS & $\begin{array}{l}\text { - Determine abort motor performance } \\
\text { - Determine attitude control motor performance } \\
\text { - Demonstrate the ability of the LAS to jettison from the crew } \\
\text { module }\end{array}$ \\
\hline Separation Events & $\begin{array}{l}\text { - Demonstrate the abort event sequencing } \\
\text { - Demonstrate the LAS-crew module separation mechanism } \\
\text { - } \text { Demonstrate the jettison of the forward bay cover } \\
\text { Obtain data on ground impact locations for the LAV modules }\end{array}$ \\
\hline Parachute & $\begin{array}{l}\text { - Demonstrate the parachute and landing system event } \\
\text { sequencing } \\
\text { - Demonstrate the deployment of the primary drogue parachute } \\
\text { and main parachute pilot chute } \\
\text { - Demonstrate the performance of the main parachute system }\end{array}$ \\
\hline Environmental & $\begin{array}{l}\text { - Determine the external acoustics environment before the LAS } \\
\text { separates from the boost protective cover } \\
\text { - Demonstrate the telemetry transmission capabilities of the } \\
\text { crew module through the boost protective cover }\end{array}$ \\
\hline Ground Support & $\begin{array}{l}\text { Demonstrate the functional performance of the command } \\
\text { control monitoring system } \\
\text { Demonstrate the functional performance of the transportation } \\
\text { handling and covers, and special tools and test equipment }\end{array}$ \\
\hline
\end{tabular}

\section{Simulation and Analysis}

A 6-degree-of-freedom nonlinear simulation, called ANTARES, has been developed by the NASA Johnson Space Center for the Crew Exploration Vehicle/Crew Launch Vehicle (CEV/CLV) operational vehicle. ${ }^{5}$ The ANTARES simulation has been modified to produce both nominal and dispersed trajectories for the flight tests and flight vehicles to be flown out of WSMR.

A sample nominal trajectory for PA-1 is shown in Fig. 5. On an abort initialization, the PA-1 vehicle pitches over to 15 degrees angle of attack, resulting in a downrange of $6900 \mathrm{ft}$. The maximum Mach obtained is 0.7 (Fig. 6), while the maximum dynamic pressure is on the order of $600 \mathrm{psf}$ (Fig. 7). Based on current simulation predictions, the altitude and downrange flight objectives for PA-1 will be successfully met during flight test.

Notional trajectory overview plots for the transonic abort (AA-2) test simulation are shown in Figs. 8-10. The transonic abort is commanded at Mach 0.99 (Fig. 8), at a dynamic pressure of $610 \mathrm{psf}$ (Fig. 9). This flight condition is where the vehicle experiences maximum drag. The transonic abort flight test reaches an altitude of 36,400 ft and obtains a downrange distance of approximately 14,000 ft (Fig. 10). 


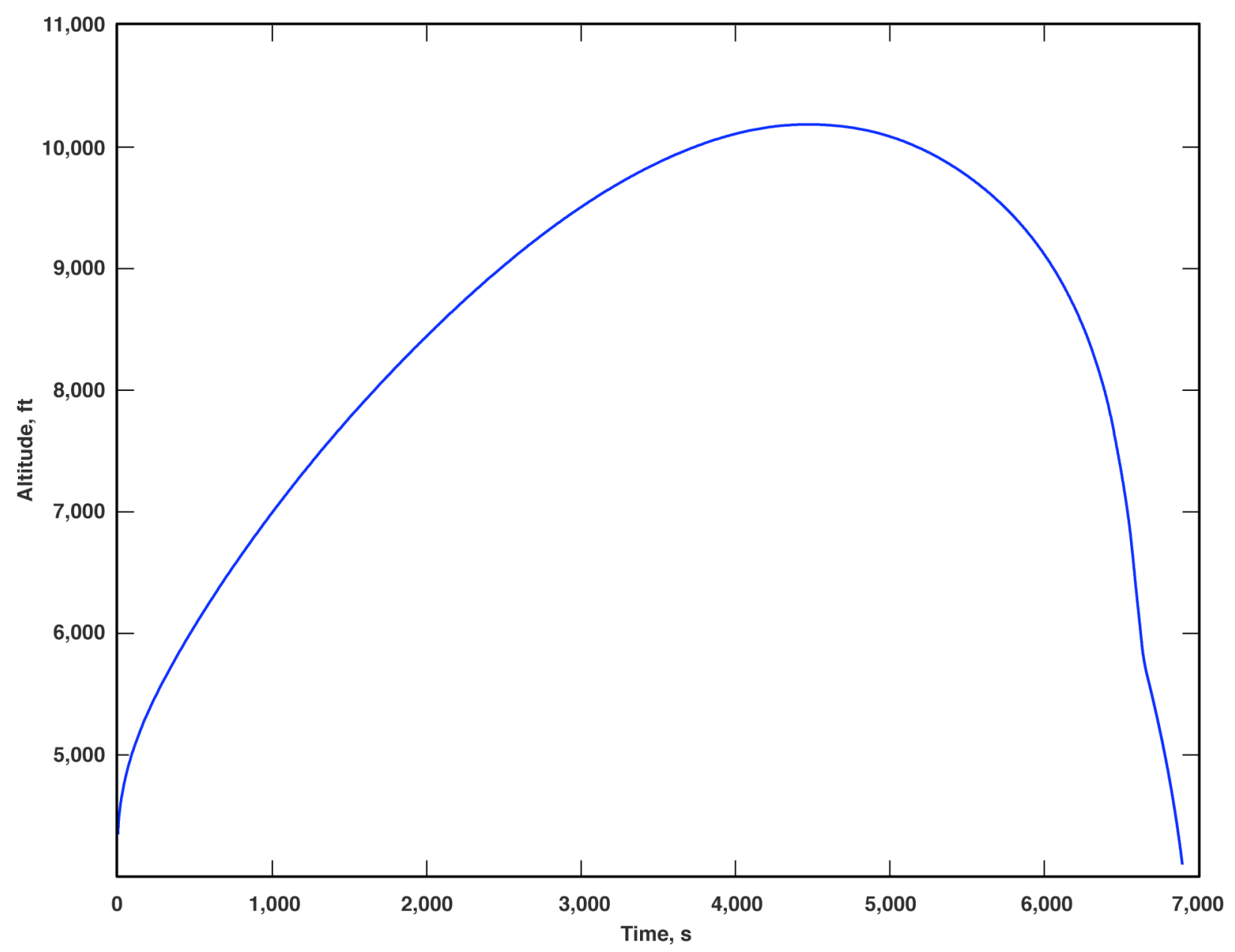

Figure 5. PA-1 nominal trajectory. 


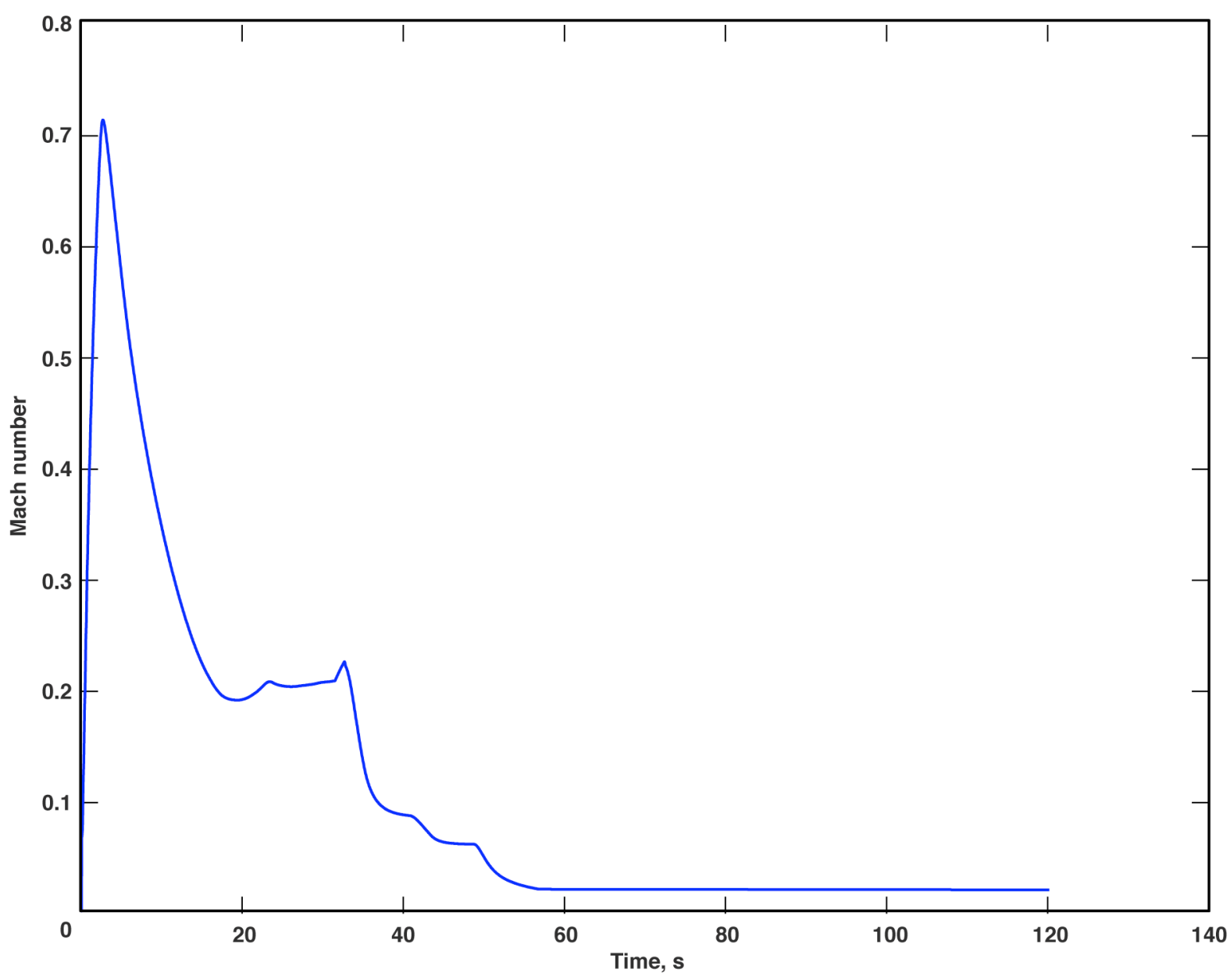

Figure 6. PA-1 Mach number. 


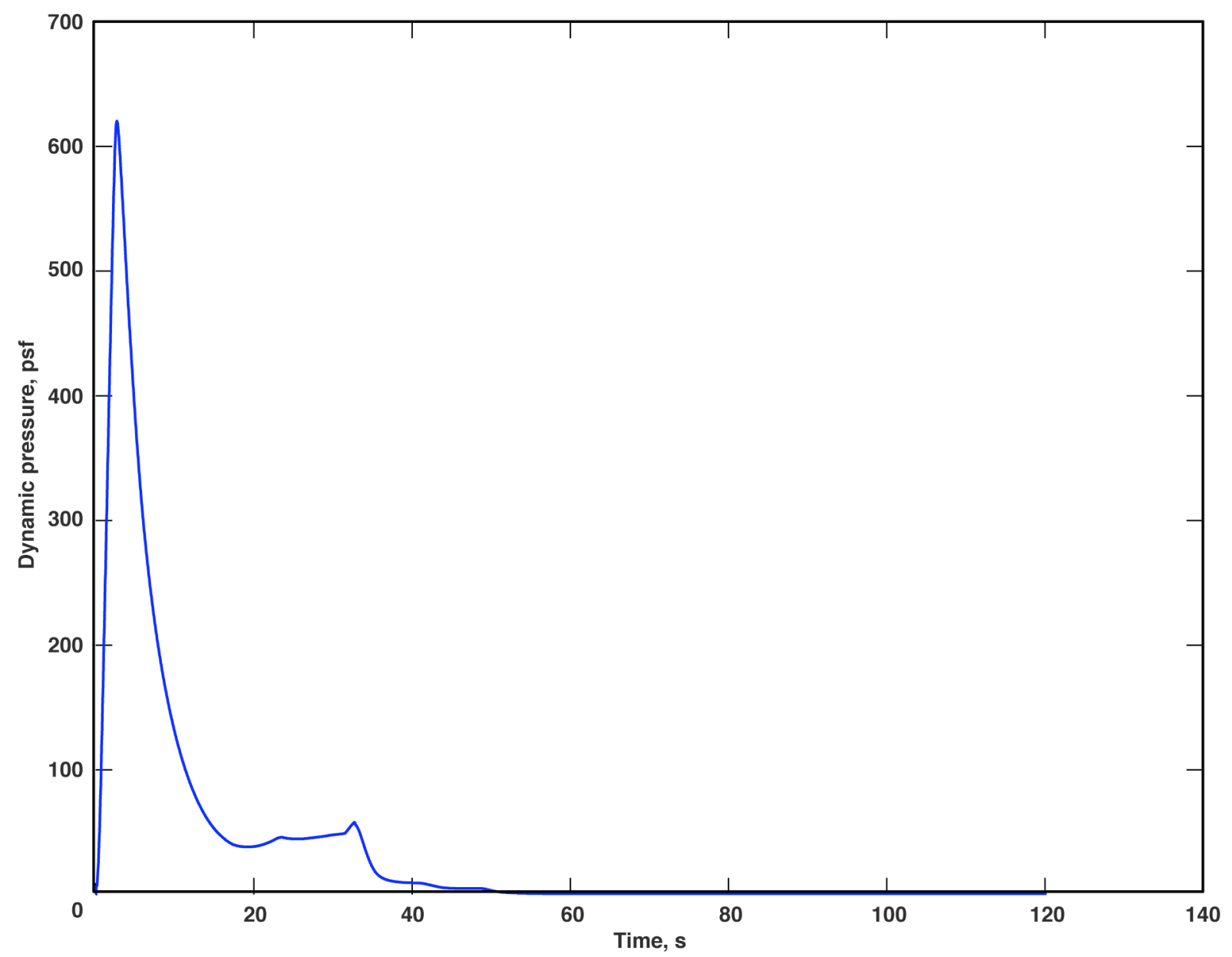

Figure 7. PA-1 dynamic pressure. 


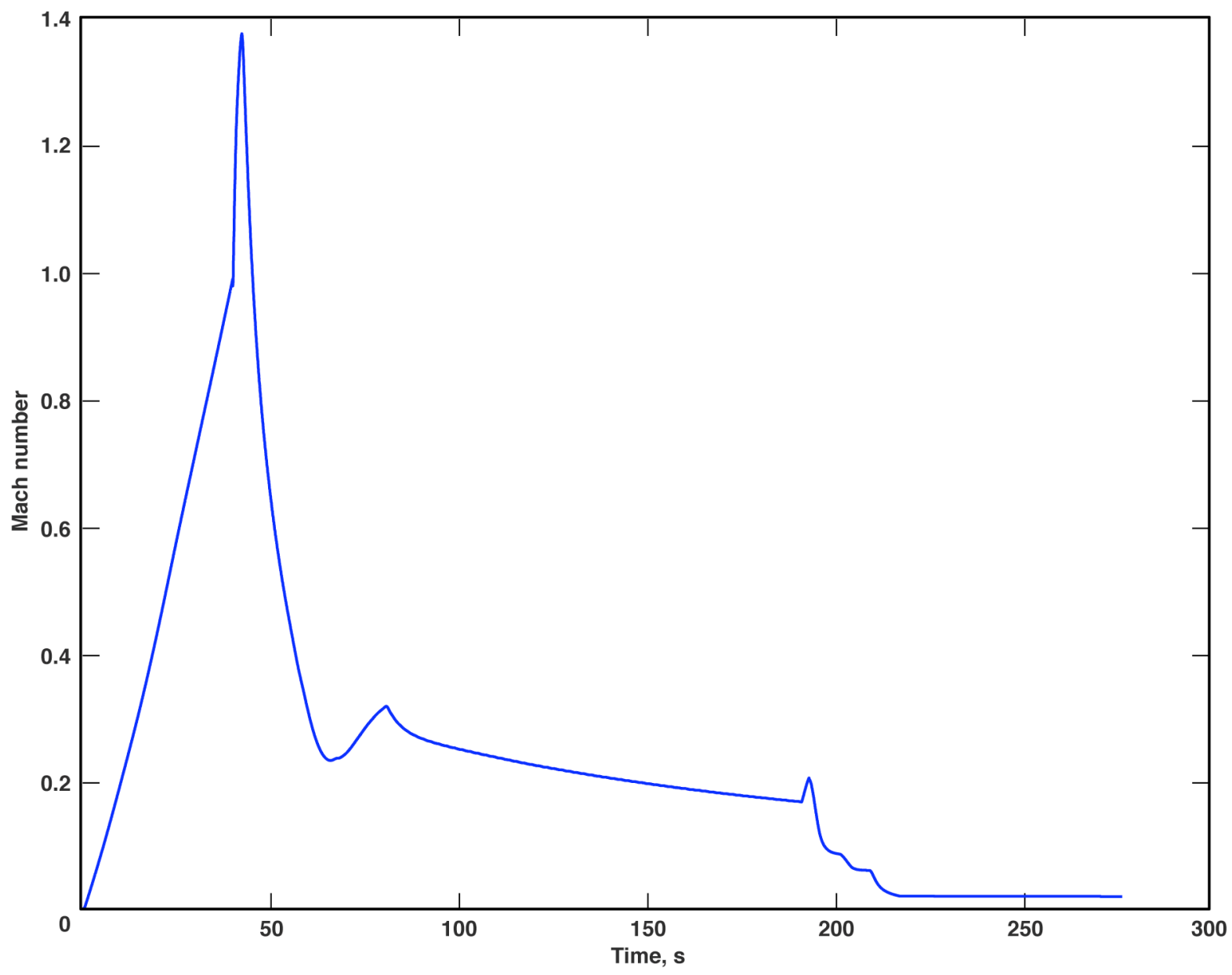

Figure 8. Transonic abort Mach number. 


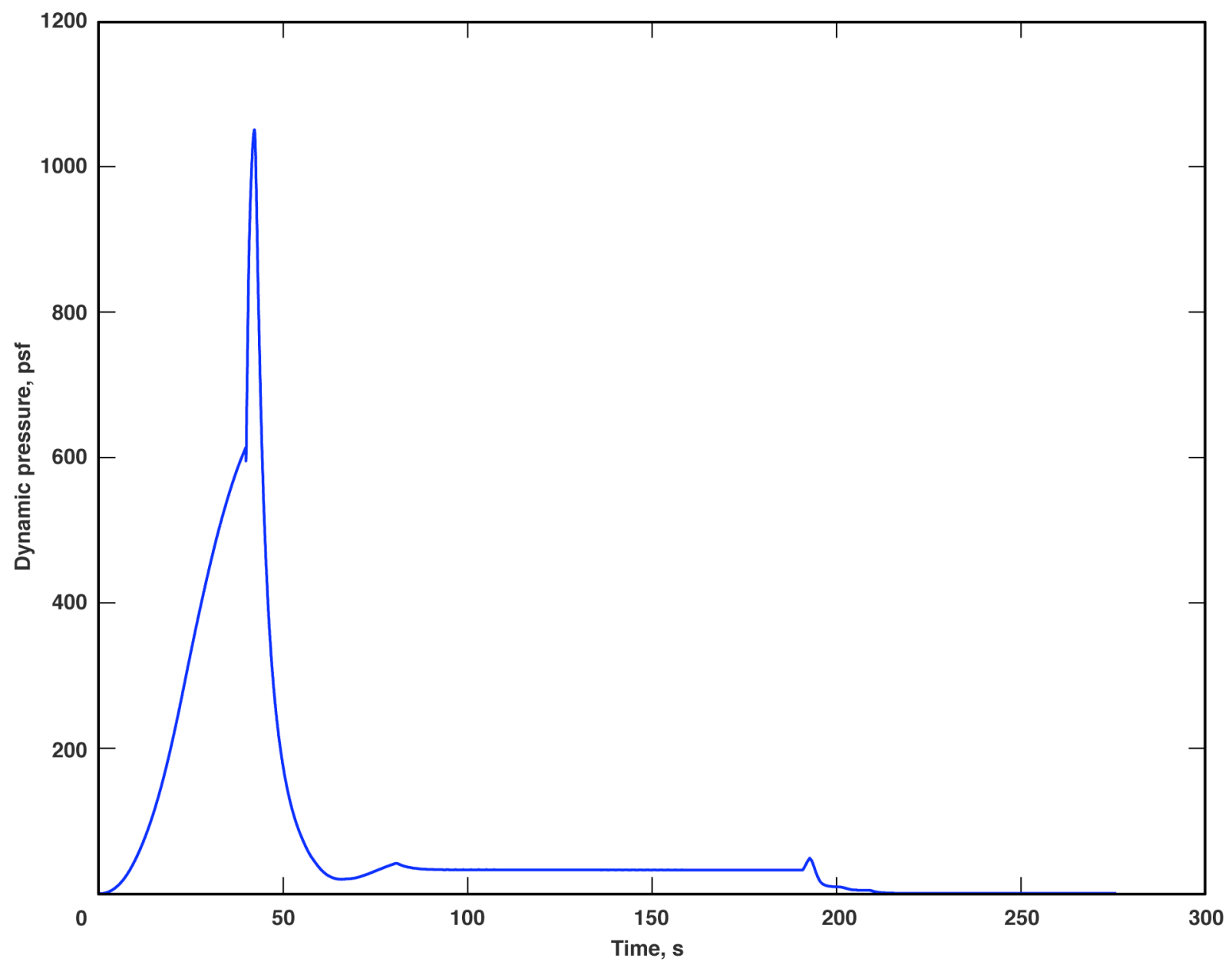

Figure 9. Transonic abort dynamic pressure. 


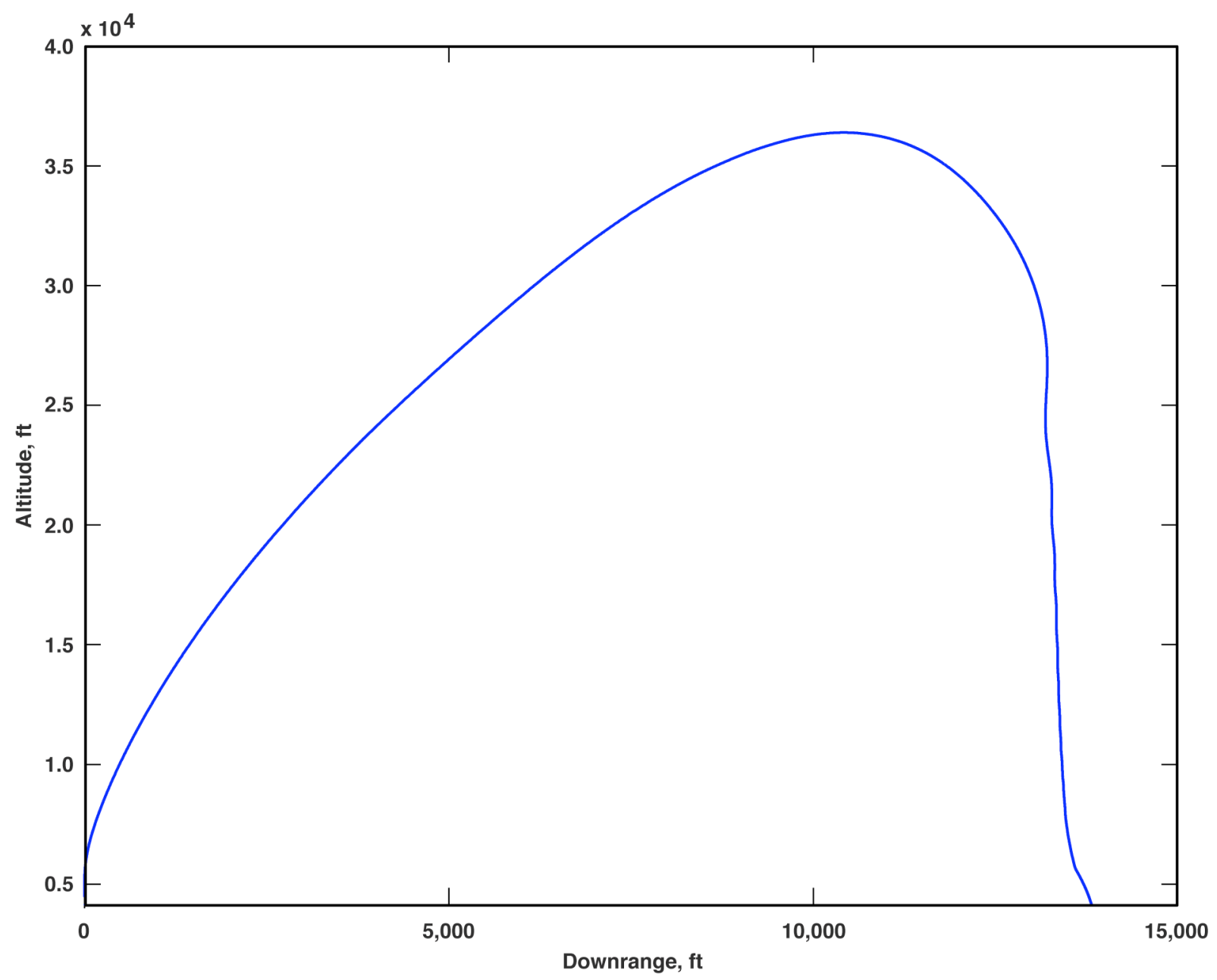

Figure 10. Notional AA-2 trajectory.

\section{Conclusion}

An overview of the LAS flight test program was provided. Vehicle configuration for the PA-1 flight test was described and details regarding the crew module, LAS, and abort test booster were provided. A nominal trajectory for the PA-1 flight test was shown. Notional nominal trajectories for the transonic AA flight test were shown and discussed, along with a description of the various flight tests taking place at WSMR. The first LAS flight test, PA-1, is scheduled to take place at White Sands, New Mexico, in September 2008.

\section{References}

${ }^{1}$ National Aeronautics and Space Administration, The Vision For Space Exploration, February 2004.

${ }^{2}$ Tamblyn, S., Hinkel, H., and Saley, D., "NASA CEV Reference GN\&C Architecture," AAS 07-071, 30th Annual AAS Guidance and Control Conference, Breckenridge, Colorado, February 3-7, 2007.

${ }^{3}$ NASA Project Apollo, Little Joe II Qualification Test Vehicle 12-50-1, GDC-63-193, September 27, 1963.

${ }^{4}$ Clarke, Robert, Flight Test Vehicle Mission and Flight Objectives, CxP 72166, January 4, 2007.

${ }^{5}$ Gay, R. and Jackson, M., "NASA ANTARES Simulation GNC Architecture," AIAA-2007-6679, AIAA Guidance, Navigation and Control Conference and Exhibit, Hilton Head, South Carolina, August 20-23, 2007 (to be published). 